\title{
Correspondence
}

\section{Psychiatrists as custodians of public safety?}

Sir: I wish to express my fullest support for Paul Bowden's editorial (Psychiatric Bulletin, February 1995, 19, 65-66). Both his editorial, and Dr Boyd's paper (Psychiatric Bulletin, February, 1995, 19, 104-105), raise a crucial ethical issue - the extent to which psychiatrists are required to protect the public from harm. It is now clear that this issue is now the legitimate concern of all psychiatrists, and not confined to forensic psychiatry.

Psychiatrists are currently being asked to do something that other law enforcement agencies are not. The Home Office is not sued when violent criminals, justly released at the end of their sentences, re-offend. Policemen are required to investigate violent crime, not prevent it, and are indemnifled against prosecution on such grounds. Psychiatrists have no such protection, and are increasingly required not only to foresee the risk of any violent crime, but also prevent it. If psychiatrists are required to act as accessory policemen, then they should have access to the same training as policemen, and the same indemnity.

To date, the right-wing press, tacitly supported by the Department of Health, has been deciding what psychiatrists' professional duties should be. They, not we, have decided that psychiatrists should be responsible for the conduct of other adults; something which is legally and philosophically unjustifiable.

As a professional group, we must wrest back the initiative, and claim some right to determine the limits of our own professional competence. Clearly, other social groups will have a part in this process. But the view of a "body of reasonable psychiatric opinion" must have greater weight than that of tabloid newspapers, if only because we can marshal years of clinical experience and research to back our claims. It is time to be bullish; if we do not get proper air-time, column space, and Parliamentary time to inform and educate the public, then we will be forced into a type of psychiatry that we thought we had left behind
40 years ago. Very few of us trained to become zookeepers or custodians of public safety, but these are the roles which are being insidiously offered as proper for a psychiatrist.

GwEN ADSHEAD, Institute of Psychiatry, Denmark Hill, London SE5 8AF

Sir: I suspect that Dr Bowden, in his editorial on the Confidential Inquiry into Homicides and Suicides by Mentally IIl People. A Preliminary Report on Homicide' (Psychiatric Bulletin February 1995, 19, 65-66) speaks more effectively for the majority of practising clinicians than Professor Sims or Dr MacKeith (Psychiatric Bulletin. March 1995, 19, 173180).

At last we know that the College's tacit acceptance of the care programme approach now enshrined in every tenet of operational policy was due to its enshrinement of "traditional values of good psychiatric practice". Where is the evidence that this theology was ever tested, quite apart from being demonstrated to have value for acute general psychiatry? Did the College ever question the absurdity of the Department's guidelines that the CPA should apply to every patient referred to the specialist mental health services and the implications of such a blunderbuss recommendation for the huge number of individuals who fleetingly encounter our junior psychiatrists in accident and emergency departments or drop-in services? Do we feel any responsibility for the disapprobation that will undoubtedly fall upon our most junior staff or the ubiquitous key-worker who will have been expected to anticipate the vagaries of the human condition and then blamed for not adhering completely to the details of the CPA and supervision register?

Some of us had hoped that the initial muscular response of the College to the Department's promulgation of the supervision register implied a recognition that documentation and bureaucracy were inappropriate substitutes for adequate resources. Unhappily it preferred the private 